\title{
Effect of subchronic intake of green tea extract on liver of albino rat histomorphometric, ultrastructural and biochemical study
}

\author{
S.M. Zaki, S.H. Ahmed, W.M. Sayed, A.A. Ali \\ Faculty of Medicine, Cairo University, Egypt \\ [Received: 17 February 2017; Accepted: 15 May 2017]
}

Background: There are conflicting reports on the effect of green tea extract (GTE) on the liver of animals. Some studies failed to show any adverse hepatic effects following administration of GTE to mice, rats, and dogs. Others reported severe hepatic necrosis, resulting in death in female Swiss-Webster mice following its administration. The aim of the study was to examine the subchronic toxicity of GTE on the liver of the adult male albino rats.

Materials and methods: Forty male adult Wistar albino rats were used in the study. The rats were divided into four groups; group I (control), group II (low-dose green tea), group III (medium-dose green tea) and group IV (high-dose green tea). Histological, biochemical and histomorphometric analyses were done.

Results: Mild hepatic affections were observed in group II. The affections were severe in groups III and IV. The central veins and hepatic sinusoids were congested. The hepatocytes were degenerated. Hypertrophy of the hepatic arteries, dilation of the bile ducts and cellular infiltration were clearly observed in the last two groups. Mild degenerative changes were observed in the hepatocytes in rat's group II; the cytoplasm was rarefied and vacuolated. Some mitochondria were ruptured. The blood sinusoids were congested. The rough endoplasmic retinaculum was fragmented in group III. More degenerative changes were observed in group IV; the hepatic architectures were lost with disruption of cell membranes. Most of the cell organelles were degenerated and most of mitochondria were ballooned. As compared to that of the control groups: the total serum protein values in groups II, III and IV showed a statistically significant decrease $(12 \%, 20 \%$ and $21 \%$, respectively), the mean area per cent of collagen fibres in groups III and IV increased 5 and 7 folds. Conclusions: Subchronic administration of GTE resulted in structural and functional affection of the rats' liver. The dose of $250 \mathrm{mg} / \mathrm{kg} /$ day seemed to be safe, while the doses of $500 \mathrm{mg} / \mathrm{kg} / \mathrm{day}$ and $1000 \mathrm{mg} / \mathrm{kg} /$ day had deleterious effect being more evident in the latter dose. (Folia Morphol 2017; 76, 4: 642-649)

Key words: green tea extract, liver

\section{INTRODUCTION}

Tea is one of the most commonly consumed drinks in the world [9]. It is divided into oolong, black and green tea according to leaf treatment [18].
Green tea is prepared by steaming immediately after gathering [24]. About $10 \%$ of the dry weight of green tea is made up of catechins (polyphenols) mainly epicatechin, epicatechin-3-gallate, 
epigallocatechin, and epigallocatechin-3-gallate (EGCG) [9].

Widespread studies have proposed that green tea and green tea polyphenols have preventive effects against cancer, diabetes, heart disease, lung damages and neurodegenerative diseases [11]. Its preventive effects on the accumulation of visceral fat had been reported [1].

The potential toxicity of green tea when administered at high doses has not been fully investigated [12]. The excessive use of green tea supplements has led to clinical cases of hepatotoxicity [24]. A case of acute liver failure linked to green tea extract (GTE) was reported from Canada [18]. Thirteen hepatic failure cases were reported (1999-2003) by the French and Spanish systems following the use of a licensed herbal medicinal product containing $80 \%$ GTE called Exolise $^{\circledR}$ [2]. The United States Pharmacopeia subsequently reviewed the safety information for green tea products. A total number of 34 reports of liver damage were found, ranging from acute hepatitis to fulminant liver failure, following the excessive use of multiple GTE preparations [24]. In one recent study, 6/1091 cases liver injury developed following administration of a GTE product called SLIMQUICK ${ }^{\circledR}$ [30]. SLIMQUICK products can lead to severe acute hepatocellular liver injury, which required or may require transplantation [30].

There are conflicting reports on the effects of GTE on the liver in animals. Some studies failed to show any adverse hepatic effects following administration of green tea to mice, rats, and dogs [2]. Others [15] reported severe hepatic necrosis, resulting in death; in female Swiss-Webster mice administered EGCG [10].

Toxicologists usually divide the exposure of animals to chemicals into four categories: acute, subacute, subchronic and chronic. Acute exposure is exposure for less than $24 \mathrm{~h}$. Subacute exposure refers to repeated exposure for 1 month or less, subchronic for 1-3 months and chronic for more than 3 months [13].

The present study is a long-term study conducted to examine the subchronic toxicity of GTE on the liver of the adult male albino rats. The liver was subjected to histological, morphometric and ultrastructural study. The morphometric studies were done using the image analyser. Clinical chemistry study of the liver function was also done through measuring the serum-enzymatic level.

\section{MATERIALS AND METHODS}

\section{Chemicals}

The GTE was made by soaking $15 \mathrm{~g}$ of instant green tea powder in $1 \mathrm{~L}$ of boiling distilled water for $5 \mathrm{~min}$ [17]. The GTE was given by gastric gavage 5 days/week for 12 weeks. This duration period is the required time to obtain information in the subchronic toxicity study [13].

\section{Animals}

Forty adult male albino Westar rats weighing 150 $-200 \mathrm{~g}$ were used in the present study. The rats were obtained from the animal house, Faculty of Medicine, Cairo University, Egypt. The animals were exposed to a light/dark cycle at $14: 10 \mathrm{~h}$ photo cycle at $22-24^{\circ} \mathrm{C}$ with a free access to food and water. The animals were cared for in accordance with the institutional ethical guidelines and protocols approved by the Experimental Ethics Committee of Cairo University.

\section{Experimental design}

The weights of each individual animal were recorded in the beginning and at week intervals until the end of the experiment. The rats were divided into four groups, 10 rats each. Ten rats per dose and three to four different dosages of the chemical to the animals are the required regimen in a typical protocol [13].

- Group I (normal control);

- Group II (low-dose green tea) - GTE was given at a dose of $250 \mathrm{mg} / \mathrm{kg} /$ day;

- Group III (medium-dose green tea) - GTE was given at a dose of $500 \mathrm{mg} / \mathrm{kg} /$ day;

- Group IV (high-dose green tea) - GTE was given at a dose of $1000 \mathrm{mg} / \mathrm{kg} /$ day.

\section{Blood sampling}

The animals were sacrificed by cervical dislocation to avoid any chemical injury [4]. Blood samples were collected from tail vein at the beginning of the experiment and immediately before dissection. The biochemical analysis included gamma-glutamyl transferase (GGT), total protein and serum albumin. The blood analysis was done at the laboratory unit of the Biochemistry Department, Faculty of Medicine, Cairo University, Egypt.

\section{Light microscopic examination}

Liver specimens were in $10 \%$ formol saline, processed for paraffin sections of 5-7 $\mu \mathrm{m}$ thickness and 


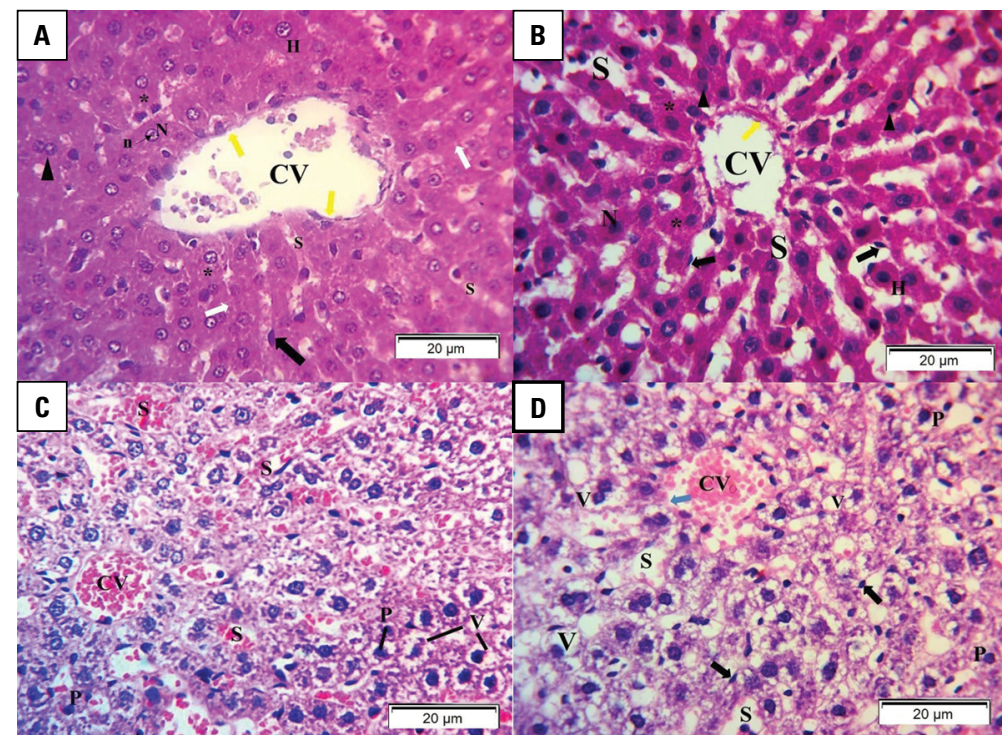

Figure 1. Liver sections around central veins in the different groups $(\mathrm{H} \& \mathrm{E} ; \times 400)$; $A$. Cords of hepatocytes (white arrows), central vein (CV) with intact endothelium (yellow arrows) and sinusoids (S) with Browicz-Kupffer cells (black arrow). The hepatocytes $(\mathrm{H})$ have normal cytoplasm $\left({ }^{*}\right)$ and nuclei (N) with central nucleolus (n). Some hepatocytes are binucleated (arrowhead) in a rat of the control group; B. Central vein (CV) with intact endothelium (yellow arrow) and mildly dilated sinusoids (S) spotted with Browicz-Kupffer cells (arrows). Normal hepatocytes $(\mathrm{H})$ with eosinophilic cytoplasm $\left(^{*}\right)$ and euchromatic nuclei (N). Few hepatocytes are bi-nucleated (arrowheads) in a rats' group II; C. Congested central vein (CV) and congested dilated sinusoids (S). Note hepatocytes with vacuolated cytoplasm (V) and pyknotic (P) nuclei in a rats' group III; D. Congested central vein (CV) with loss of continuity of lining endothelium (blue arrows). Hepatocytes exhibit vacuolated cytoplasm (V) and pyknotic nuclei (P). Browicz-Kupffer cells (arrows) in the wall of dilated sinusoids $(S)$ in a rats' group IV.

mounted on glass slides for histopathological examination. They were stained with haematoxylin and eosin (H\&E) stain to study the changes in histological architecture and Masson's trichrome stain to demonstrate the collagen fibres.

\section{Electron microscopic examination}

Specimens from the liver were fixed in $4 \%$ glutaraldehyde then washed in phosphate buffer and post fixed in $1 \%$ osmium tetraoxide. Fixation was followed by dehydration and embedding in epoxy resins. Semithin sections $(1 \mu \mathrm{m})$ were stained with toluidine blue. Ultrathin sections (50-60 nm) were stained with uranyl acetate and lead citrate. These sections were examined and photographed using a Joel, 100 CX II transmission electron microscope.

\section{Histomorphometric studies}

Quantitative data were obtained using "Leica Qwin 500 C" image analyser computer system Ltd. (Cambridge, England). The area per cent of collagen fibres was measured.

\section{Statistical analysis}

Statistical analysis was performed using statistical package for the social sciences (SPSS) version 21.0 (IBM Corporation, Somers, NY, USA) statistical software. The data were expressed as means \pm standard deviation (SD). Statistical evaluation was done using one-way analysis of variance (ANOVA) followed by Bonferroni pairwise comparisons. Significance was considered when $p$ value was less than 0.05 . The percentages of increase or decrease (difference) in all studied parameters were calculated according to the following formula:

$$
\begin{gathered}
\text { Percentage } \\
\text { of difference }
\end{gathered}=\frac{\begin{array}{c}
\text { Mean difference value } \\
\text { between two groups }
\end{array}}{\begin{array}{c}
\text { Value of the } \\
\text { compared group }
\end{array}} \times 100
$$

\section{RESULTS}

\section{Histological and ultrastructural observation}

The liver of the control group showed normal histological architecture around the central vein (Fig. 1A). Mild changes were observed in group II (Fig. 1B). In contrary, severe changes were observed in groups III and IV. The central veins and hepatic sinusoids were congested. Degeneration of the hepatocytes in the form of cytoplasmic vacuolations and nuclear pyknosis were also noticed (Fig. 1C, D).

The portal area of the control rat showed normal histological pattern (Fig. 2A). The portal veins were dilated with irregular intact endothelium in group II (Fig. 2B). The portal veins were congested, the bile ducts were dilated, the hepatic arteries are thickened with the presence of cellular infiltration in groups III and IV (Fig. 2C, D).

The collagen fibres increased slightly in the rat's group II, while these fibres increased obviously in the rat's groups III and IV. These changes observed around the central veins (Fig. 3) and in the portal areas around the portal veins, bile ductules and hepatic arteries (Fig. 4).

Mild degenerative changes were observed in the hepatocytes in rat's group II; the cytoplasm showed rarefaction and vacuolations. Some mitochondria were 

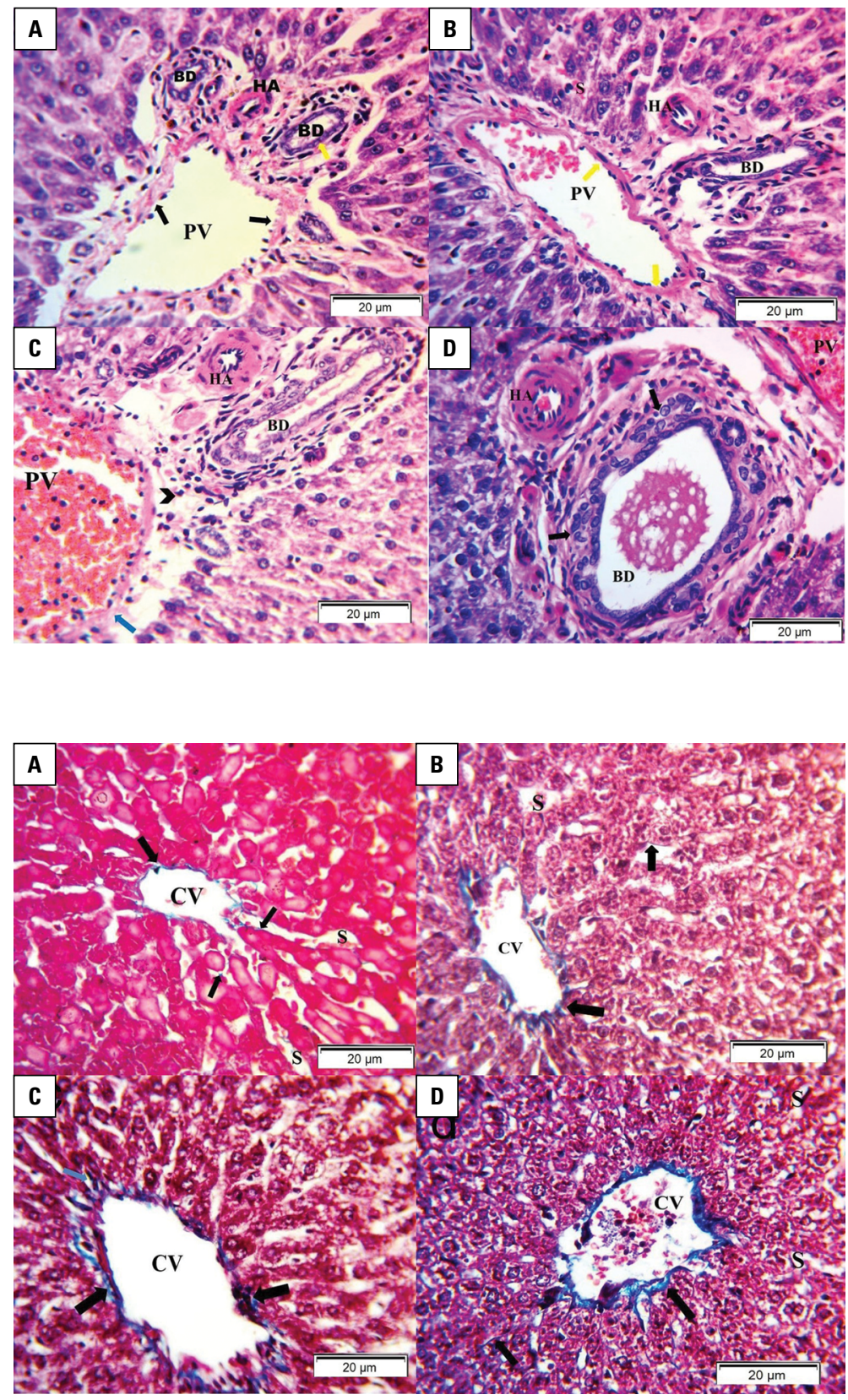

Figure 2. Liver sections around portal area in the different groups $(\mathrm{H} \& \mathrm{E} ; \times 400)$; A. Portal vein radicle (PV) with intact endothelium (black arrows), hepatic artery (HA) and bile ductule (BD) lined with cuboidal epithelium (yellow arrow) in a rat of the control group; B. Dilated portal vein (PV) with irregular intact endothelium (yellow arrow). Hepatic artery (HA), bile ductule (BD) and sinusoids (S) are normal in a group II rat; C. Dilated congested portal vein (PV) with disturbed lining endothelium (blue arrow). Hypertrophy of hepatic artery (HA) and dilated bile duct (BD) are noticed. Note cellular infiltration (arrowhead) around bile duct in a group III rat; D. Proliferation of epithelial lining (arrow) of the bile duct (BD), thickened hepatic artery $(\mathrm{HA})$ and congested portal vein (PV) in a group IV rat.
Figure 3. Liver sections showing collagen fibres (arrows) around central vein (CV) and in the wall of blood sinusoids $(S)$ in the different groups (Masson's trichrome; $\times 400$ ); A. Minimal amount of collagen fibres in the control group; B. Slight increase the collagen fibres in the rat's group II; C, D. Increase amount of collagen fibres the rat's groups III and IV, respectively. ruptured. The blood sinusoids were congested, BrowiczKupffer cells engulfed dead cells and the bile canaliculi were dilated. Beside these changes, the rough endoplasmic retinaculum was fragmented in group III. More degenerative changes were observed in group IV; the hepatic architectures were lost with disruption of cell membranes. Most of the cell organelles were degenerated and most of mitochondria were ballooned. The blood sinusoids were filled with blood and exudate (Figs. 5, 6).

\section{Biochemical results (Tables 1, 2)}

Results revealed non-significant difference in serum albumin and GGT levels among the different studied groups. The total serum protein values in groups II, III and IV showed a statistically significant decrease (12\%, $20 \%$ and $21 \%$, respectively) as compared to that of the control group. The protein value of group III decreased $8 \%$ as compared to that of the group II.

\section{Morphometric measurements (Tables 1, 3, 4)}

The mean area per cent of collagen fibres in group III increased about 5 folds as compared to that of the control groups. In addition, the area per cent of fibrosis in group IV increased about 7 folds as compared to that of the control group and about 1.5-fold as compared to that of group II. 


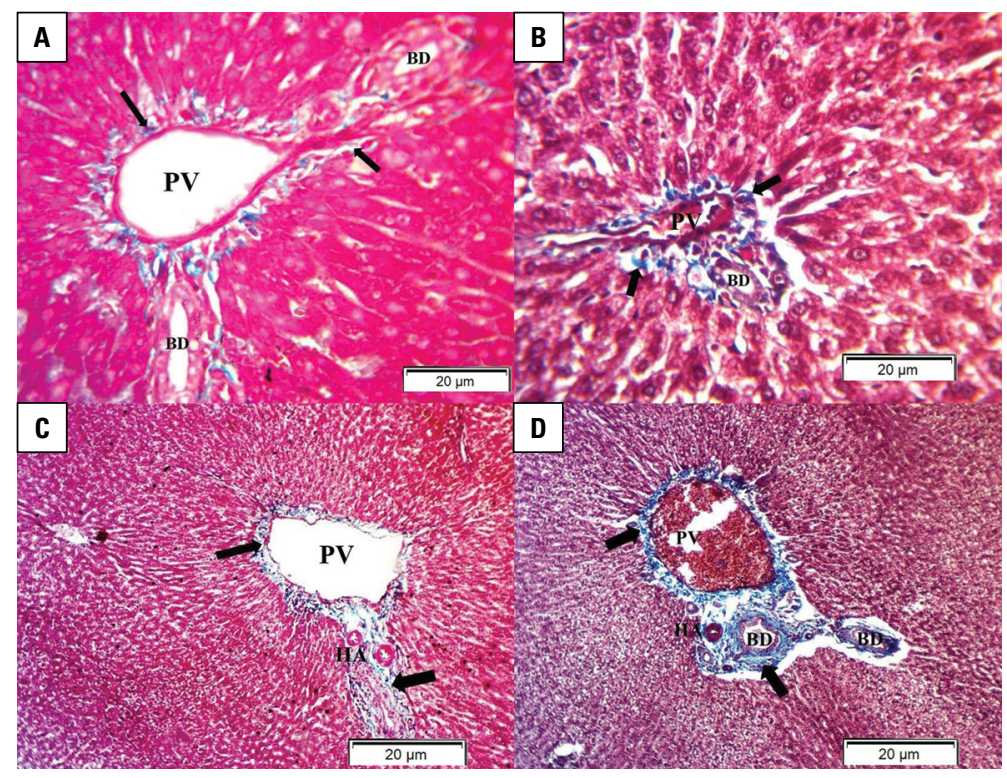

Figure 4. Liver sections showing collagen fibres (arrows) in the portal area around the portal vein radicle $(\mathrm{PV})$, bile ductule $(\mathrm{BD})$ and hepatic artery (HA) (Masson's trichrome); A. Minimal amount of collagen fibres in the control group $(\times 400)$; B. Slight increase the collagen fibres in the rat's group II $(\times 400)$; C, D. Increase amount of collagen fibres the rat's groups III and IV, respectively $(\times 100)$.

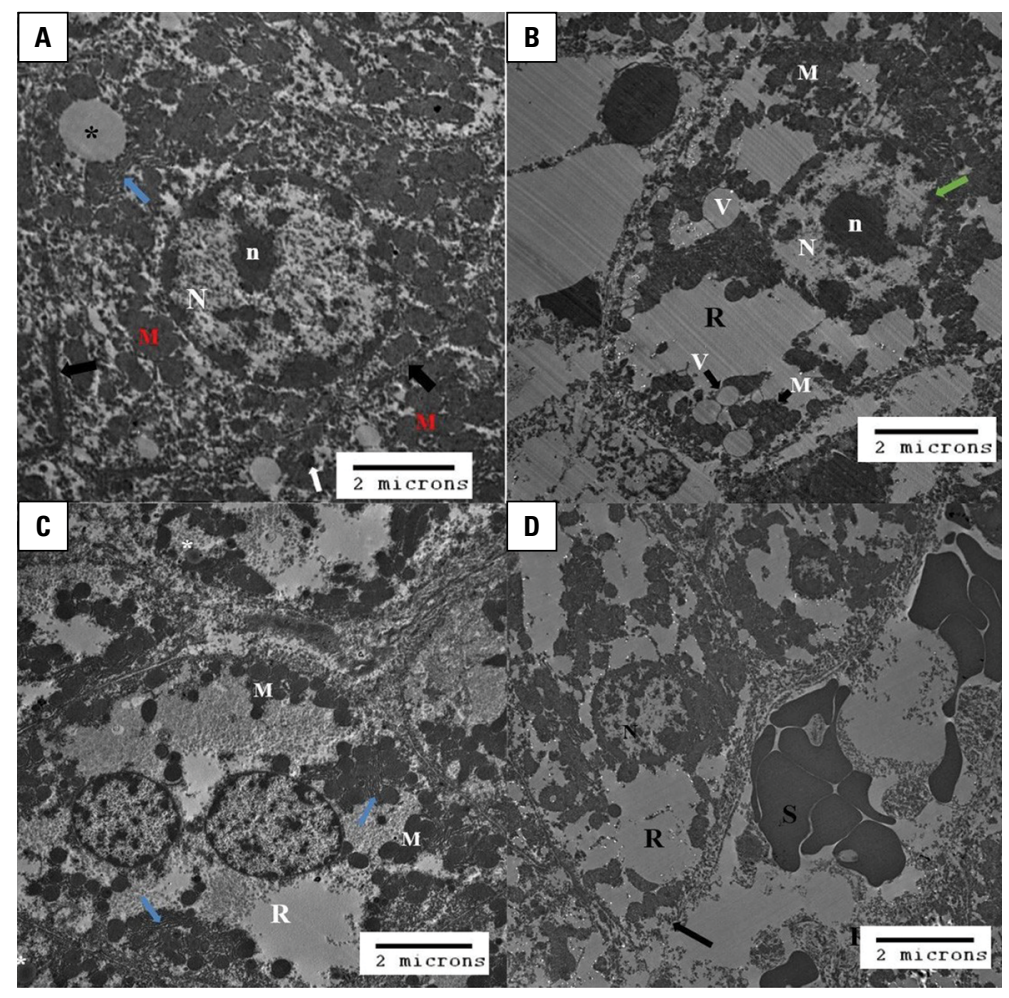

Figure 5. Electron photomicrograph of the hepatocytes in the different groups; A. Hepatocyte's cytoplasm with abundant mitochondria (M), rough endoplasmic retinaculum (blue arrows), lysosomes (white arrow) and fat droplets $\left(^{*}\right)$. The cell membrane is intact (black arrows). Normal nucleus (N) with central nucleolus $(n)$ in the control group $(E M ; \times 3000)$; B. Rarefaction (R) and vacuolation (V) of the cytoplasm. Mitochondria (M) are intact. The nucleus (N) shows nucleolus (n) and exhibits peripheral condensation of chromatin (green arrow) in a rat's group II $(E M ; \times 4000)$; C. Binucleated hepatocyte with rarefied cytoplasm (R), fragmented rough endoplasmic retinaculum (blue arrows) and intact mitochondria (M). Lysosomes can be spotted $\left({ }^{*}\right)$ in a rat's group III (EM; $\left.\times 3000\right)$; D. Loss of hepatic architecture with disrupted cell membrane (arrow). Cytoplasmic rarefaction (R) with degeneration of most cell organelles. The nucleus $(\mathrm{N})$ is heterochromatic and shows islands of chromatin. Congested dilated sinusoid (S) in a rat's group IV (EM; $\times 3000)$; EM — lead acelate.

\section{DISCUSSION}

There were no signs of morbidity or mortality noticed all over the studied groups. These results matched the results of many authors $[3,12]$. In contrary, some authors reported $60 \%$ premature mortality of the animals in their study [23], while others reported $12 \%$ mortality in their study [5].
Functional affection of the liver in our study was observed at different doses. The total protein and serum albumin levels $(\mathrm{g} / \mathrm{dL}$ ) were the more relevant biochemical parameters. These results match with the results of other researchers [3]. The increase in GGT levels was only significant in group VI. Mazzanti et al. (2015) found abrupt elevation in GGT levels up to $394 \mathrm{U} / \mathrm{L}$ [16]. 


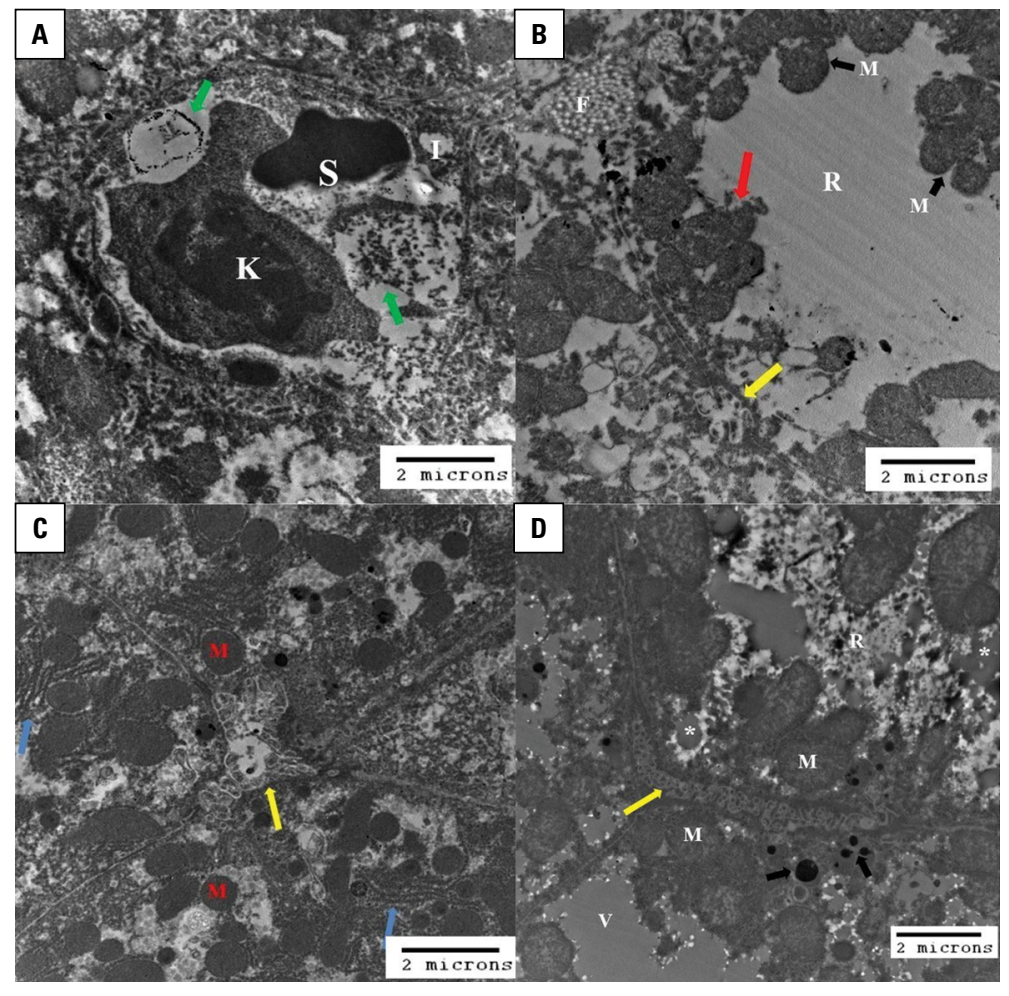

Figure 6. Electron photomicrograph of the liver sections in the different groups; $\mathbf{A}$. Congested blood sinusoid (S), Browicz-Kupffer cell (K) engulfing dead cells (green arrows) and Ito cell (I) in a rat's group II ( $\times 10000)$; B. Rarefaction of cytoplasm (R). Some mitochondria (M) are intact while others are ruptured (red arrow). Note: dilated bile canaliculus (yellow arrow) and collagen fibres $(F)$ in a rat's group II $(\times 12000)$; C. Dilated bile canaliculus (yellow arrow), intact mitochondria (M) and intact rough endoplasmic reticulum (blue arrows) in a rat's group III $(\times 8000)$; D. Vacuolated (V) and rarefied $(\mathrm{R})$ cytoplasm. Swollen ballooned mitochondria (M) with loss of cristae. Lipid droplets $\left({ }^{*}\right)$, lysosomes (black arrows) and bile canaliculus (yellow arrow) in a rat's group IV (EM; $\times 8000)$.

Table 1. Mean value of the biochemical tests' results at the time of sacrifice in the experimental groups

\begin{tabular}{lcccccc}
\hline Test & Group I & Group II & Group III & Group IV & \multicolumn{2}{c}{ ANOVA } \\
\cline { 5 - 7 } & & & & & F value & P value \\
\hline Serum albumin (mean \pm SD) [g/dL] & $4.20 \pm 0.00$ & $3.96 \pm 0.3$ & $3.92 \pm 0.3$ & $3.89 \pm 0.3$ & 3.481 & $<0.015^{*}$ \\
Total protein (mean \pm SD) [g/dL] & $6.60 \pm 0.10$ & $5.77 \pm 0.5$ & $5.27 \pm 0.5$ & $5.2 \pm 0.5$ & 42.714 & $<0.001^{*}$ \\
GGT (mean \pm SD) [U/L] & $16.90 \pm 025$ & $20.28 \pm 1.15$ & $22.32 \pm 1.78$ & $24.45 \pm 2.73$ & 4.466 & $<0.004^{*}$ \\
\hline
\end{tabular}

*P value $>0.05$ is significant; GGT — gamma-glutamyl transferase

Table 2. Mean difference of total protein of the experiment groups at the time of sacrifice

\begin{tabular}{llcc}
\hline Group I & Group J & MD (I-J) & Significant \\
\hline \multirow{3}{*}{ Group I } & Group II & $0.83000^{*}$ & $<0.001$ \\
& Group III & $1.33000^{*}$ & $<0.001$ \\
& Group IV & $1.40000^{*}$ & $<0.001$ \\
\hline \multirow{3}{*}{ Group II } & Group I & $-0.83000^{*}$ & $<0.001$ \\
& Group III & $0.50000^{*}$ & $0.02^{*}$ \\
& Group IV & $0.57000^{*}$ & $0.007^{*}$ \\
\hline \multirow{3}{*}{ Group III } & Group I & $-1.33000^{*}$ & $<0.001$ \\
& Group II & $-0.50000^{*}$ & $0.02^{*}$ \\
& Group IV & 0.07000 & 1.000 \\
\hline \multirow{3}{*}{ Group IV } & Group I & $-1.40000^{*}$ & $<0.001$ \\
& Group II & $-0.57000^{*}$ & $0.007^{*}$ \\
& Group III & -0.07000 & 1.000 \\
\hline
\end{tabular}

${ }^{*}$ The mean difference is significant at the 0.05 level; MD — mean difference
Our different experimental groups exhibited variable degrees of hepatic affection. This could be attributed to the oxidative stress induced by the GTE [15].

In our study, necrotic changes of hepatocytes were more prominent in group IV. The necrotic hepatocytes started in the portal area then extended to the centrilobular region. This centrilobular to pan-lobular necrosis pattern matched the findings of others $[3,5]$.

Congestion of sinusoids, central and portal veins, with prominence of Browicz-Kupffer cells started to appear in groups III and IV. All these lesions didn't reflect severe liver injury [22]. The portal congestion may be result of swollen periportal cells that compress the adjacent sinusoids and resist blood passage within the sinusoids, causing back-pressure on the portal vein radicles [26]. 
Table 3. Mean and standard deviation of values of area per cent of collagen fibres in the experimental groups

\begin{tabular}{lcccccc}
\hline Test & Group I & Group II & Group III & Group IV & \multicolumn{2}{c}{ ANOVA } \\
\cline { 3 - 7 } & & & & & F value & P value \\
\hline Area \% of fibrosis (means \pm SD) & $1.49 \pm 0.6$ & $5.23 \pm 2.7$ & $8.80 \pm 2.3$ & $11.90 \pm 2.2$ & 42.129 & $<0.001^{*}$ \\
\hline${ }^{*}$ P value $>0.05$ is significant & & & & &
\end{tabular}

Table 4. Mean difference of the area $\%$ of fibrosis in the experimental groups

\begin{tabular}{llcc}
\hline & Group J & MD (I-J) & Significant \\
\hline \multirow{3}{*}{ Group I } & Group II & -3.74400 & 0.080 \\
& Group III & $-7.29200^{*}$ & $<0.001$ \\
& Group IV & $-10.36600^{*}$ & $<0.001$ \\
\hline \multirow{3}{*}{ Group II } & Group I & 3.74400 & 0.080 \\
& Group III & -3.54800 & 0.112 \\
& Group IV & $-6.62200^{*}$ & $<0.001$ \\
\hline \multirow{3}{*}{ Group III } & Group I & $7.29200^{*}$ & $<0.001$ \\
& Group II & 3.54800 & 0.112 \\
& Group IV & -3.07400 & 0.252 \\
\hline \multirow{2}{*}{ Group IV } & Group I & $10.36600^{*}$ & $<0.001$ \\
& Group II & $6.62200^{*}$ & $<0.001$ \\
& Group III & 3.07400 & 0.252 \\
\hline
\end{tabular}

${ }^{*}$ The mean difference is significant at the 0.05 level; MD — mean difference

The portal tract region showed areas of cellular infiltrations in group IV. This infiltration indicates the immune response of the body towards the cellular damage [21].

Bile duct proliferation was also noticed in group IV. Bile duct proliferation is associated with hepatic injury [28]. The increased biliary pressure is the initiating factor in the bile duct cell division [28]. The bile ductules in the portal tracts contained progenitor cells that had a higher capability to proliferate and could give rise to hepatocytes or biliary cells [25].

Fibrotic changes were observed in the portal region and the wall of blood sinusoids in groups III and IV. The activated portal fibroblasts, Ito cells and myofibroblasts had been recognised as major collagen-producing cells in the injured liver [27]. These cells could be activated by fibrogenic cytokines secreted by the biliary cells in response to irritation by toxins [27].

Cytoplasmic vacuolations are present in GTE-studied groups, being more prominent in group IV. These vacuolations could be due to accumulation of water inside the intoxicated cells [29]. The vacuolations could be fat globules pushing the nuclei peripherally, giv- ing a signet-ring appearance in the light microscopic study and exhibiting cores of low electron density with electron lucent outlines in the ultrastructural study [8]. Lipid droplets are dynamically regulated organelles that serve as energy resources and lipid storage compartments. So, accumulation of fat droplets in hepatocytes of the intoxicated rats could be a compensatory mechanism by which the cells try to preserve some energy after destruction of the mitochondria [14].

The nuclei of the hepatocytes in group IV showed loss of the nucleoli, with marked reduction of the chromatin content and peripheral condensation of the chromatin. The nucleoli are the most sensitive parts of the nuclei, and the first parts to deteriorate under different forms of stress [20].

The perisinusoidal Ito cells in group IV were devoid of fat droplets, which indicated that these cells have lost their function as fat-storing cells. The Ito cells in our study were elongated and adopted fibroblast-like configuration, with deposition of collagen in the adjacent area. This finding supported many studies that reported that after liver injury of any cause, Ito cells are transformed from a quiescent fat-storing state into activated cells which could produce extracellular matrix proteins, such as collagen and proteoglycan [6, 7].

The aetiology of the hepatotoxicity induced by GTE is still unknown. However, the catechins and their gallic acid esters, predominantly EGCG seemed to be the components responsible for the hepatotoxicity [16]. EGCG's major cytotoxic mechanism is mitochondrial membrane potential collapse and reactive oxygen species formation [9].

Average consumption of green tea (2-3 times per day) appears safe [24]. Moderate drinking of green tea is not the cause of concern; it is the tablet/capsular form of the pure EGCG or the GTE products that have risen up questions about its safety [19].

\section{CONCLUSIONS}

In conclusion, it was found that subchronic administration of GTE in albino rats resulted in structural 
and functional affection of the liver. The dose of $250 \mathrm{mg} / \mathrm{kg} /$ day seemed to be safe, while the doses of $500 \mathrm{mg} / \mathrm{kg} / \mathrm{day}$ and $1000 \mathrm{mg} / \mathrm{kg} /$ day had deleterious effect being more evident in the latter dose.

Recommendation: the average consumption of green tea in the form of aqueous solution appears to be harmless as it takes at least 3 cups of green tea/ day, providing a minimum of $250 \mathrm{mg} /$ day catechins. On the other hand, consumption of concentrated GTE in the form of tablets may lead to hepatotoxicity in high doses.

\section{REFERENCES}

1. Bajerska J, Wozniewicz M, Jeszka J, et al. Green tea aqueous extract reduces visceral fat and decreases protein availability in rats fed with a high-fat diet. Nutr Res. 2011; 31(2): 157-164, doi: 10.1016/j.nutres.2011.01.005, indexed in Pubmed: 21419320.

2. Bun SS, Bun H, Guédon D, et al. Effect of green tea extracts on liver functions in Wistar rats. Food Chem Toxicol. 2006; 44(7): 1108-1113, doi: 10.1016/j.fct.2006.01.006, indexed in Pubmed: 16487645.

3. Chan PoC, Ramot Y, Malarkey DE, et al. Fourteen-week toxicity study of green tea extract in rats and mice. Toxicol Pathol. 2010; 38(7): 1070-1084, doi:10.1177/0192623310382437, indexed in Pubmed: 20884815.

4. Ding SP, Li JC, Jin C. A mouse model of severe acute pancreatitis induced with caerulein and lipopolysaccharide. World J Gastroenterol. 2003; 9(3): 584-589, indexed in Pubmed: 12632523.

5. Emoto Y, Yoshizawa K, Kinoshita Y, et al. Green Tea Extractinduced Acute Hepatotoxicity in Rats. J Toxicol Pathol. 2014; 27(3-4): 163-174, doi: 10.1293/tox.2014-0007, indexed in Pubmed: 25378801.

6. Fausther M, Lavoie EG, Dranoff JA. Contribution of myofibroblasts of different origins to liver fibrosis. Curr Pathobiol Rep. 2013; 1(3): 225-230, doi: 10.1007/s40139013-0020-0, indexed in Pubmed: 23997993.

7. Forbes SJ, Parola M. Liver fibrogenic cells. Best Pract Res Clin Gastroenterol. 2011; 25(2): 207-217, doi: 10.1016/j. bpg.2011.02.006, indexed in Pubmed: 21497739.

8. Fujimoto $T$, Ohsaki Y, Suzuki M, et al. Imaging lipid droplets by electron microscopy. Methods Cell Biol. 2013; 116: 227-251, doi: 10.1016/B978-0-12-408051-5.00012-7, indexed in Pubmed: 24099296.

9. Galati G, Lin A, Sultan AM, et al. Cellular and in vivo hepatotoxicity caused by green tea phenolic acids and catechins. Free Radic Biol Med. 2006; 40(4): 570-580, doi: 10.1016/j.freeradbiomed.2005.09.014, indexed in Pubmed: 16458187

10. Goodin MG, Rosengren RJ. Epigallocatechin gallate modulates CYP450 isoforms in the female Swiss-Webster mouse. Toxicol Sci. 2003; 76(2): 262-270, doi: 10.1093/ toxsci/kfh001, indexed in Pubmed: 14600287.

11. Higdon JV, Frei B. Tea catechins and polyphenols: health effects, metabolism, and antioxidant functions. Crit Rev Food Sci Nutr. 2003; 43(1): 89-143, doi: 10.1080/10408690390826464, indexed in Pubmed: 12587987

12. Hsu YW, Tsai CF, Chen WK, et al. A subacute toxicity evaluation of green tea (Camellia sinensis) extract in mice. Food Chem Toxicol. 2011; 49(10): 2624-2630, doi: 10.1016/j. fct.2011.07.007, indexed in Pubmed: 21771628.

13. Klaassen CD, Watkins JB, Casarett U. Casarett \& Doull's essentials of toxicology. 2nd ed. McGraw-Hill Medical Pub. Division, New York: 2010: pxi, 459.
14. Kühnlein RP. Thematic review series: Lipid droplet synthesis and metabolism: from yeast to man. Lipid droplet-based storage fat metabolism in Drosophila. J Lipid Res. 2012; 53(8): 1430-1436, doi: 10.1194/jlr.R024299, indexed in Pubmed: 22566574.

15. Lambert JD, Kennett MJ, Sang S, et al. Hepatotoxicity of high oral dose (-)-epigallocatechin-3-gallate in mice. Food Chem Toxicol. 2010; 48(1): 409-416, doi: 10.1016/j. fct.2009.10.030, indexed in Pubmed: 19883714.

16. Mazzanti G, Di Sotto A, Vitalone A. Hepatotoxicity of green tea: an update. Arch Toxicol. 2015; 89(8): 1175-1191, doi: 10.1007/s00204-015-1521-x, indexed in Pubmed: 25975988.

17. Mehdipour M, Daghigh Kia H, Najafi A, et al. Effect of green tea (Camellia sinensis) extract and pre-freezing equilibration time on the post-thawing quality of ram semen cryopreserved in a soybean lecithin-based extender. Cryobiology. 2016 [Epub ahead of print]; 73(3): 297-303, doi: 10.1016/j.cryobiol.2016.10.008, indexed in Pubmed: 27983946.

18. Molinari M, Watt KDS, Kruszyna T, et al. Acute liver failure induced by green tea extracts: case report and review of the literature. Liver Transpl. 2006; 12(12): 1892-1895, doi: 10.1002/lt.21021, indexed in Pubmed: 17133573.

19. Nagao $T$, Komine $Y$, Soga $S$, et al. Ingestion of a tea rich in catechins leads to a reduction in body fat and malondialdehyde-modified LDL in men. Am J Clin Nutr. 2005; 81(1): 122-129, indexed in Pubmed: 15640470.

20. Nagata T. Senescence. Rijeka (HR): InTech,; 2012. Available from: http://www.ncbi.nlm.nih.gov/books/NBK402330/.

21. Patel SS, Beer S, Kearney DL, et al. Green tea extract: a potential cause of acute liver failure. World J Gastroenterol. 2013; 19(31): 5174-5177, doi: 10.3748/wjg.v19.i31.5174, indexed in Pubmed: 23964154.

22. Saleh IG, Ali Z, Abe N, et al. Effect of green tea and its polyphenols on mouse liver. Fitoterapia. 2013; 90: 151-159, doi: 10.1016/j.fitote.2013.07.014, indexed in Pubmed: 23892001.

23. Salminen $W F$, Yang $X i$, Shi $Q$, et al. Green tea extract can potentiate acetaminophen-induced hepatotoxicity in mice. Food Chem Toxicol. 2012; 50(5): 14391446, doi: 10.1016/j.fct.2012.01.027, indexed in Pubmed: 22306919.

24. Sarma DN, Barrett ML, Chavez ML, et al. Safety of green tea extracts : a systematic review by the US Pharmacopeia. Drug Saf. 2008; 31(6): 469-484, indexed in Pubmed: 18484782.

25. Sell S. The hepatocyte: heterogeneity and plasticity of liver cells. Int J Biochem Cell Biol. 2003; 35(3): 267-271, indexed in Pubmed: 12531236.

26. Serov VV. [Nature of cloudy swelling and granular degeneration of parenchymatous organs]. Arkh Patol. 1991; 53(2): 3-6, indexed in Pubmed:2069523.

27. Shi J, Hao JH, Ren WH, et al. Effects of heparin on liver fibrosis in patients with chronic hepatitis B. World J Gastroenterol. 2003; 9(7): 1611-1614, indexed in Pubmed: 12854176.

28. SlottPA, Liu MH, Tavoloni N. Origin, pattern, and mechanism of bile duct proliferation following biliary obstruction in the rat. Gastroenterology. 1990; 99(2): 466-477, indexed in Pubmed: 1694804.

29. Zhang $F, X u X, L i T$, et al. Shellfish toxins targeting voltage-gated sodium channels. Mar Drugs. 2013; 11(12): 4698-4723, doi: 10.3390/md11124698, indexed in Pubmed: 24287955.

30. Zheng EX, Rossi S, Fontana RJ, et al. Risk of Liver Injury Associated with Green Tea Extract in SLIMQUICK(®) Weight Loss Products: Results from the DILIN Prospective Study. Drug Saf. 2016; 39(8): 749-754, doi: 10.1007/s40264016-0428-7, indexed in Pubmed: 27189593. 